ERDC FY17 Level II Leadership Development Program

\title{
A Proposed Knowledge, Skills, and Abilities (KSA) Database Tool for ERDC-CERL
}

Ryan R. Busby, Donna R. Cockburn, Leslie M. Gioja,

May 2018

Patrick J. Guertin, James P. Miller, and Tapan C. Patel

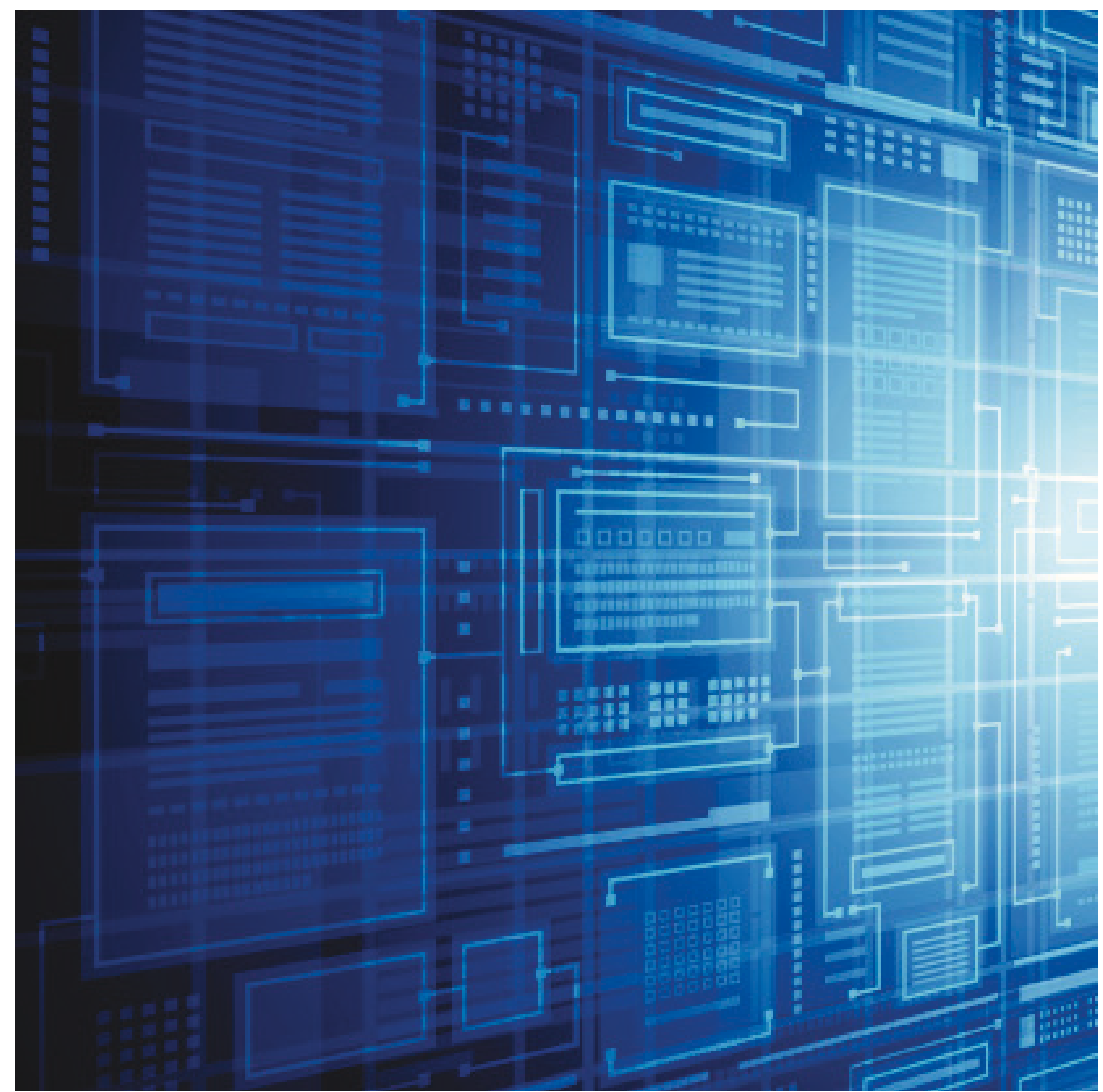


The U. S. Army Engineer Research and Development Center (ERDC) solves the nation's toughest engineering and environmental challenges. ERDC develops innovative solutions in civil and military engineering, geospatial sciences, water resources, and environmental sciences for the Army, the Department of Defense, civilian agencies, and our nation's public good. Find out more at www. erdc. usace. army. mil.

To search for other technical reports published by ERDC, visit the ERDC online library at http://acwc. sdp. sirsi. net/client/default. 


\section{A Proposed Knowledge, Skills, and Abilities (KSA) Database Tool for ERDC-CERL}

Ryan R. Busby, Donna R. Cockburn, Leslie M. Gioja, Patrick J. Guertin, James P. Miller, and Tapan C. Patel

Construction Engineering Research Laboratory

U. S. Army Engineer Research and Development Center 2902 Newmark Drive

Champaign, IL. 61822

Final report

Approved for public release; distribution is unlimited.

Prepared for Engineer Research and Development Center Construction Engineering Research Laboratory 2902 Newmark Drive Champaign, IL 61822

Under ERDC-Champaign Level 2 Leadership Development Program 


\section{Abstract}

Since the Engineer Research and Development Center's Construction Engineering Research Laboratory (ERDC-CERL) operates within a relatively fast-paced business world, often with short and rigid execution schedules, researchers need to quickly assemble effective teams with the right knowledge, skills, and abilities (KSAs) to timely complete high-quality work. Persons within ERDC-CERL may have the needed KSAs, but locating them currently and quickly can be challenging.

\section{ERDC-CERL's FY17 Level II Leadership Development Program (LDP2) team recommends addressing the lack of a central repository for ERDC- CERL employees' KSAs, because lack of such information often leads to outsourcing and missed opportunities for in-house teaming among ERDC- CERL personnel. After considering a number of ideas, the LDP2 team de- veloped a database that would enable ERDC-CERL employees to docu- ment their unique capabilities and qualifications, and it would also enable project managers, researchers, and others to search the database for per- sons with KSAs that could be useful on future project teams.}

The team's concept is compared to past and present ERDC tools and to commercially available KSA database tools. The team concludes that its database concept is superior, but it also identifies needed refinements before laboratory-wide deployment.

DISCLAIMER: The contents of this report are not to be used for advertising, publication, or promotional purposes. Citation of trade names does not constitute an official endorsement or approval of the use of such commercial products. All product names and trademarks cited are the property of their respective owners. The findings of this report are not to be construed as an official Department of the Army position unless so designated by other authorized documents. 


\section{Contents}

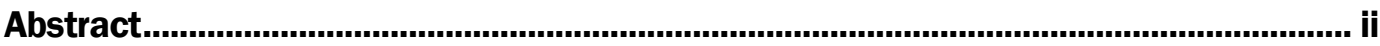

Figures and Tables.................................................................................................................

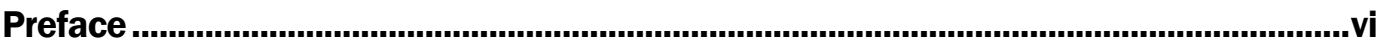

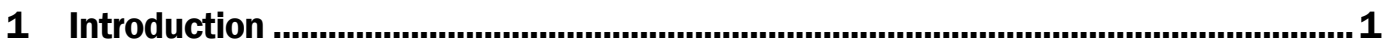

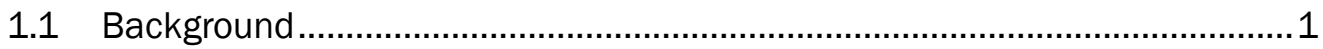

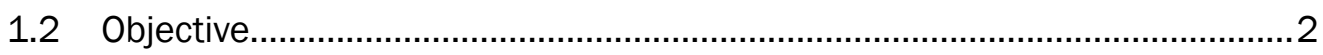

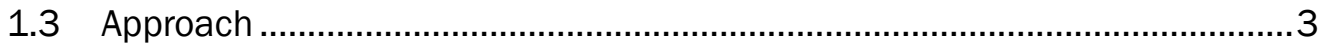

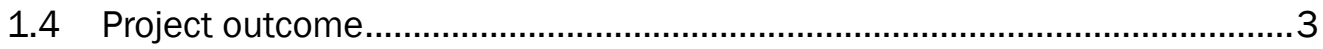

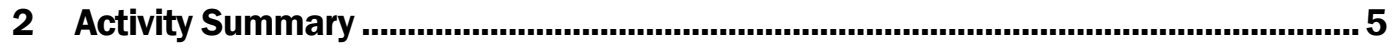

2.1 Group discussions and problem identification .............................................

2.2 Initial presentation to ERDC-CERL leadership ............................................

2.3 Branch meeting presentations and discussions ........................................6

2.4 RForum meeting ............................................................................. 7

2.5 Development of prototype database with employee engagement................. 7

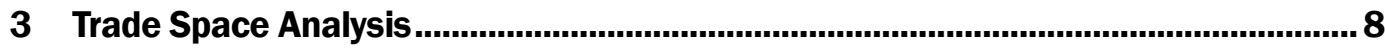

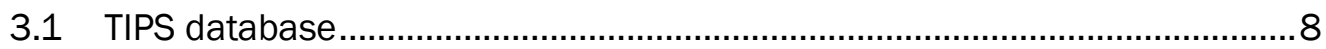

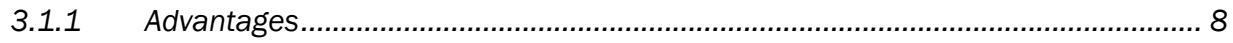

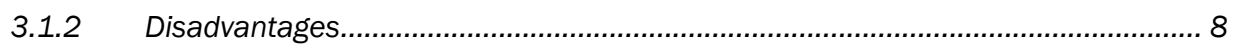

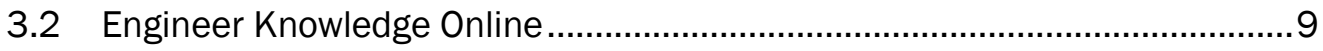

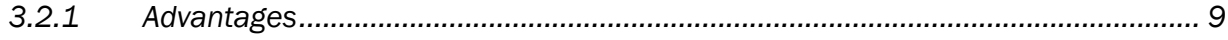

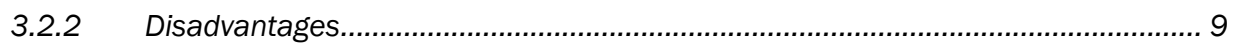

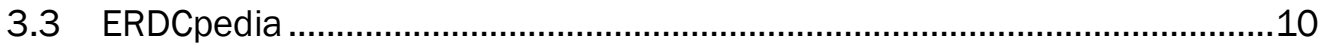

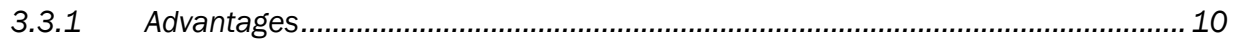

3.3.2 Disadvantages............................................................................................. 11

3.4 Craig Technologies employee KSA tool ....................................................11

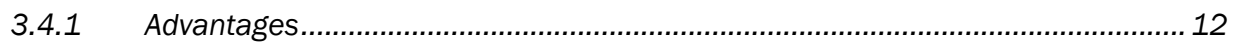

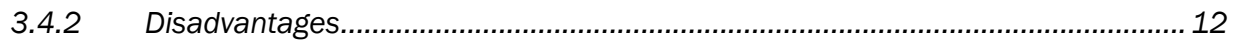

3.5 Skills DB Pro KSA tool ........................................................................... 12

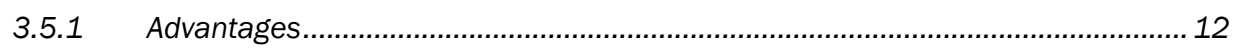

3.5.2 Disadvantages........................................................................................... 13

3.6 Cold Regions Research and Engineering Laboratory initiative................... 13

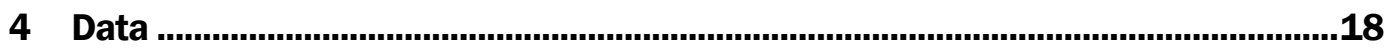

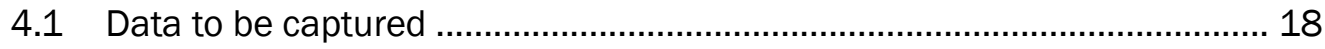

4.1.1 Contact information ....................................................................................... 19

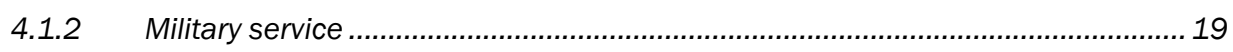

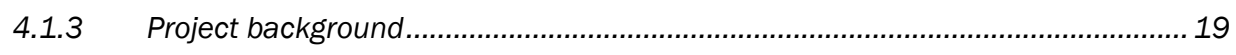

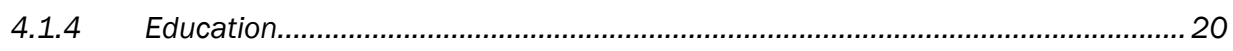

4.1.5 Skills/Professional Licenses ........................................................................... 20 


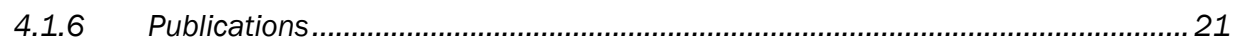

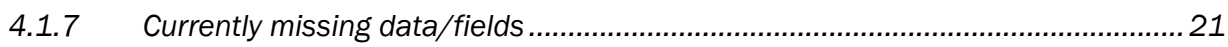

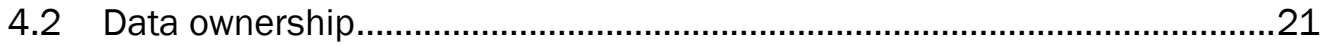

4.3 Data validation.................................................................................. 22

4.4 PII issues and concerns ................................................................. 22

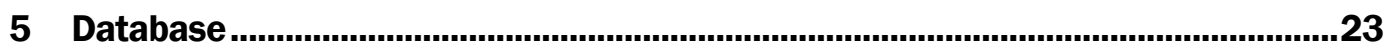

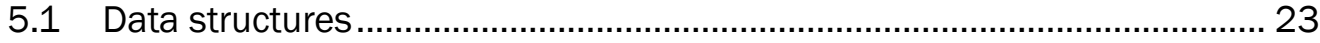

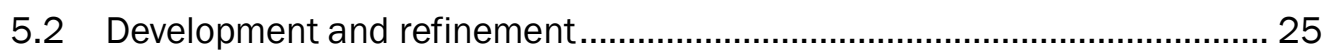

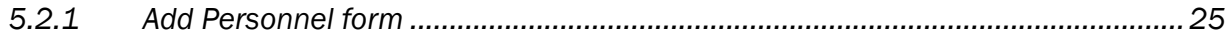

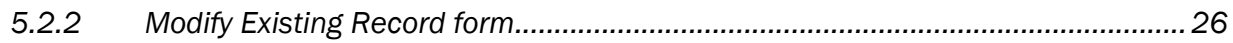

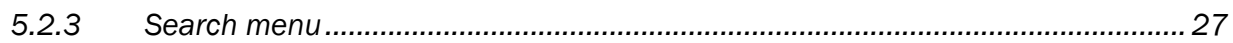

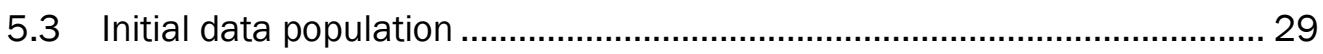

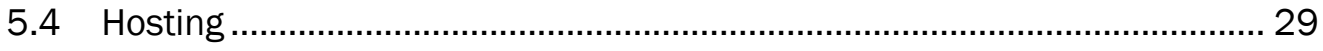

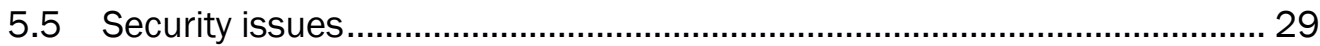

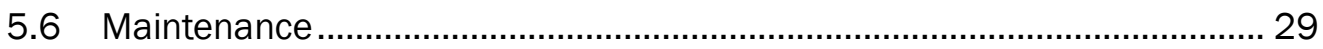

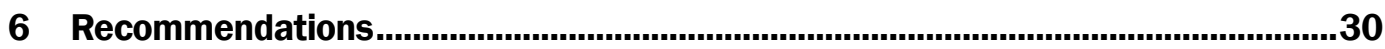

6.1 Pre-deployment refinement ............................................................ 30

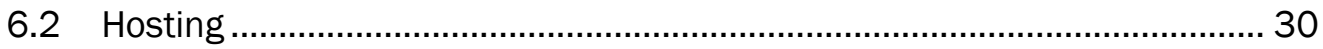

6.3 Ownership of the KSA tool ..................................................................... 30

6.4 Further development and maintenance of the KSA tool............................ 30

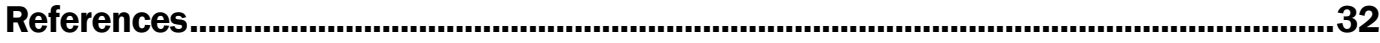

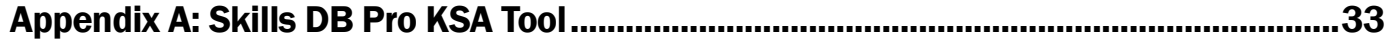

Report Documentation Page 


\section{Figures}

\section{Figures}

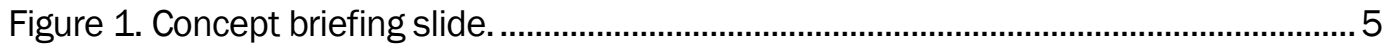

Figure 2. Engineer Knowledge Online (EKO) home page................................................10

Figure 3. ERDCpedia home page. ..................................................................................11

Figure 4. Craig Technologies employee KSA tool home page ()........................................12

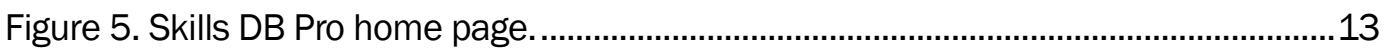

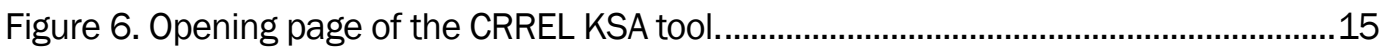

Figure 7. Examples of Employee Profile data fields in the ERDC-CRREL KSA tool. ............15

Figure 8. Search results for all employees currently listed as "Computer Scientist."

Figure 9. Partial search results - employees currently listed as "Research Physical Scientist."

Figure 10. Architectural framework for the ERDC-CERL KSA tool. .....................................23

Figure 11. Database architecture for ERDC-CERL KSA database. ......................................24

Figure 12. Main menu page of ERDC-CERL's “ASK CERL” KSA database. ...........................25

Figure 13. The Add Personnel data input form..................................................................26

Figure 14. The Modify Personnel data input screen............................................................2

Figure 15. The Report Search Menu screen...................................................................28

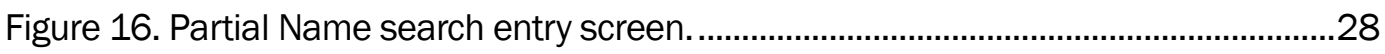

Figure 17. Search by Last Name results screen. ...............................................................28 


\section{Preface}

This report serves as the closeout project for the Level II Leadership Development Program (LDP2) team of the U. S. Army Engineer Research and Development Center - Construction Engineering Research Laboratory (ERDC-CERL). The technical monitor was Dr. George Calfas, CEERDCNE.

The work was performed by team members from the Energy Branch (CFE) of the Facilities Division (CF), the Ecological Processes Branch (CNN) of the Installations Division (CN), the Public Works Branch (PWF-EC) and the Management Integration Office (CZM) of ERDC-CERL. Oversight of the project was provided by CZM. At the time of publication, Ms. Dawn King was ERDC-CERL's Management Integration Officer (CEERD-CZM). The Deputy Director of ERDC-CERL was Dr. Kirankumar Topudurti, and the Director was Dr. Lance D. Hansen.

COL Bryan S. Green was the Commander of ERDC, and Dr. David Pittman was the Director. 


\section{Introduction}

\subsection{Background}

The Engineer Research and Development Center-Construction Engineering Research Laboratory (ERDC-CERL) is an organization whose mission is to "Develop and infuse innovative technology to provide excellent facilities and realistic training lands for Army installations and the Department of Defense." ERDC-CERL is one of seven research laboratories that comprise ERDC, which is headquartered in Vicksburg, Mississippi. To accomplish its mission, ERDC-CERL employs scientists, engineers, and technicians from numerous disciplines and a full spectrum of support staff to accomplish a very broad, diverse range of research and development activities. Most ERDC-CERL employees share at least a basic proficiency in common skill sets such as the use of the Outlook enterprise email service, other Microsoft Office products, Adobe Acrobat and the like; however, there are many tasks at ERDC-CERL that require unique knowledge, skills, and abilities (KSAs) to perform successfully. For example, certain ERDC-CERL tasks may require the use of very specialized software tools or complex laboratory equipment. Most ERDC-CERL employees couldwith enough time, effort, and training-become proficient at all tasks associated with their research. However, in many instances, trying to develop proficiency in all tasks is not an effective use of time or resources. As a result, employees wisely seek out existing expertise when it is needed to efficiently accomplish their work.

ERDC-CERL's employee population is quite diverse in terms of age, expertise, and experience. There are many late-career persons who have successfully completed a number of challenging projects. In many cases, they know how to navigate the intricacies of the Army organization and the U.S. Army Corps of Engineer (USACE) business environment. They may also be experts in accomplishing certain tasks by using tried and true, but sometimes outdated, methods. These employees might benefit from taking advantage of new skills and methods that early-career employees bring to the table. Conversely, early-career employees might benefit from the practical skills of more experienced workers.

ERDC-CERL employees are also diverse in their personal and professional backgrounds. For example, ERDC-CERL's personnel have backgrounds 
that range from numerous engineering disciplines to various life sciences (biology, botany, ecology, etc.) to social scientists, information scientists, business and administrative professionals, and other disciplines. On occasion, an engineer, for example, might benefit from the knowledge and skills of a person with a social science or administrative background.

One of the characteristics of the ERDC-CERL work environment is that many employees work on very small teams, often with people from their own branch or work group. As a result, the tendency is to be quite familiar with the capabilities within small work groups, while remaining somewhat unfamiliar with the skills and expertise available within other parts of the organization. Although social activities, cross-disciplinary projects, and other activities alleviate this problem somewhat, it remains a characteristic of the ERDC-CERL work environment.

Because ERDC-CERL operates within a relatively fast-paced business world, often with short and/or rigid execution schedules, researchers have to quickly assemble effective teams with the right KSAs to complete highquality work in a timely manner. In many cases, the needed KSAs exist within ERDC-CERL's workforce, but locating the individuals who possess them can be challenging. As a result, project managers and researchers often resort to finding those capabilities outside of ERDC-CERL via private contractors or other government agencies. In doing so, ERDC-CERL funding is sent outside the organization, capable ERDC-CERL employees miss opportunities to collaborate within the organization, and sometimes ERDC-CERL researchers find themselves unable to cover their own labor costs.

ERDC's Level II Leadership Development Program (LDP2) is a program designed to aid employees in the identification and development of their leadership skills. It "provides employees the opportunity to apply those skills through direct interaction with ERDC leadership and by participation in management-related functions." The program's curriculum includes completing a team project that establishes a method to address a leadership or management issue facing the organization.

\subsection{Objective}

The objective of ERDC-CERL's FY17 LDP2 team project was to provide a recommendation to address the lack of a central repository for ERDCCERL employees' KSAs. By establishing such a KSA repository, ERDC- 
CERL's program managers, project managers, and principal investigators would be better supported, and the skills of researchers, administrative staff, and other employees would be identified and available to be effectively used across the ERDC-CERL organization.

\subsection{Approach}

In order to address the lack of a central repository for KSAs, an initial review was done of tools that have been tried in the past to capture similar information. A gap analysis was completed, considering the pros and cons of several types of commercially available KSA tools and database tools available within the government. The next step was to engage the ERDCCERL staff to solicit buy-in to the need for this tool and their input into the types of information they would find helpful to capture. The team met with several branches during their regular branch meetings as well as with ERDC-CERL's Researchers' Forum (RForum). The RForum is a voluntary group of researchers who meet regularly to discuss problems and concerns of common interest to seek solutions and propose ideas for improvement to ERDC-CERL management.

A prototype database was developed for what such a KSA tool might look like, and its functionality was tested. This database was created in Microsoft Access which allowed easier mapping of the various data fields and a demonstration to ERDC-CERL's Leadership Council (LC) of how this tool would work was conducted. This prototype database was made available to part of the ERDC-CERL staff for voluntary input to help shape the data fields for the proposed KSA tool.

The final product of the FY17 LDP2 team is this report, which documents the results and insights gained from exploring past KSA tools, examining commercially available KSA tools, examining database tools available within the government, and soliciting input from the workforce. This report also recommends a path forward for implementation of a repository for KSAs.

\subsection{Project outcome}

This project resulted in a prototype KSA tool that could be further developed and refined for implementation at ERDC-CERL. The team envisioned the tool being common access card (CAC)-accessible and hosted on ERDC-CERL's internal SharePoint site. Profile data for each employee 
would be "owned" by the individual employee so that they have full access permissions (read/write/edit/delete) over their own profile, but employees have read-only permission for all others' profiles.

To be most effective, ERDC-CERL's KSA tool should be a voluntary tool and not a requirement. To become effectively used, this tool needs to satisfy the perceived interests and needs of the workforce and show its value to them. To do that, overall ownership of the tool should be given to representatives of the workforce, possibly the RForum. The RForum could solicit feedback from the workforce regarding enhancements and improvements that could add value to the tool.

The ERDC-CERL KSA tool is presently not ready for deployment to the workforce. Further refinements beyond the capabilities of the LDP2 team are needed. After reviewing ERDC database management salaries, the team estimated that a week of a skilled database developer's time (approximately $\$ 4 \mathrm{k}$ ) would be adequate to prepare this tool for initial deployment to the workforce. In addition, approximately two days of a skilled database developer's time (approximately $\$ 1.6 \mathrm{k}$ ) was estimated to cover costs of annual updates and enhancements. 


\section{Activity Summary}

\subsection{Group discussions and problem identification}

The fiscal year 2017 (FY17) LDP2 team kicked off its year by meeting on several occasions to discuss a team project that would be beneficial to the ERDC-CERL organization.

After considering a number of candidate ideas, the LDP2 team proposed developing a database that would enable ERDC-CERL employees to document their unique capabilities and qualifications. The proposed database would then enable project managers, researchers, and others to search the database for persons with KSAs that might be useful on their project teams.

\subsection{Initial presentation to ERDC-CERL leadership}

The team prepared an initial briefing to share their proposed concept with ERDC-CERL's leadership. This overall concept (Figure 1), was presented to ERDC-CERL's Leadership Council (LC) on 16 December 2016.

Figure 1. Concept briefing slide.

\section{PROPOSED PROJECT IDEA}

Objective: Improve CERL's ability to identify/utilize Knowledge, Skills and Abilities (KSAs) within the CERL workforce

Problem:

- KSAs within CERL frequently not visible to researchers and managers needing access to those KSAs

- Researchers/managers seek KSAs outside of CERL without realizing they are available within the Lab

- Managers lack a useful tool to allow them to analyze CERL KSA base in order to develop it

CERL Benefits:

- Improved productivity by utilizing expertise already existent within CERL's workforce

- Reduced outsourcing of CERL work and resources

- Improved corporate capabilities as CERL KSA gaps are identified and addressed

Proposed Product:

- Brief report and presentation to CERL management

- Outline a process/funding requirements etc.

- Implement a framework (as time/resources available) 
Feedback from the LC briefing included the following suggestions:

- Interview new employees after 2 months, 6 months, and 1 year.

- Interview outgoing employees.

- Synchronize with other ERDC or USACE initiatives, such as the following:

- ERDC Link

- Note: ERDC Link may not have personnel info

- ERDCpedia

- USACE Technical Excellence Network (TEN)

- Engineer Knowledge Online (EKO)

- Consider available commercial off-the-shelf (COTS) and government off-the-shelf (GOTS) products.

- Envision the resulting database and its related considerations as being those listed below:

- Make database searchable (use of key words).

- Make database updatable and able to be validated.

- Consider database as a resume database.

- Consider using a web crawler ${ }^{1}$ to search the database.

- Avoid mission creep. Focus efforts on an ERDC-CERL tool (not all of ERDC) at this point.

- Enlist inputs from the RForum, ERDC-CERL branches, and others to define KSAs and desirable features.

- Carefully avoid issues with personally identifiable information (PII) and other types of sensitive information.

\subsection{Branch meeting presentations and discussions}

In March 2017, members of the LDP2 team met with employees from two of the six ERDC-CERL research branches and the Management Integration Office (MIO) to solicit their opinions and ideas on the project. Feedback from these discussions included the following:

- There was clear interest among the ERDC-CERL staff in developing some type of database for employees to document their KSAs.

\footnotetext{
${ }^{1} \mathrm{~A}$ web crawler is an internet bot that systematically browses the web for indexing purposes.
} 
- There was interest in being able to post papers, reports, articles, and other accomplishments as a means of marketing employee capabilities to the Department of Defense (DoD) community and beyond.

\subsection{RForum meeting}

Additionally, a meeting with ERDC-CERL's RForum group was held on 6 April 2017. RForum members were onboard with the need and desire for such a tool. Much of this meeting was spent reviewing the existing capabilities of EKO. This discussion helped to narrow the team's focus to developing a tool specifically designed for ERDC-CERL's internal use rather than for use by people external to the organization.

\subsection{Development of prototype database with employee engagement}

After all initial findings, discussions, and input, the team developed a prototype database in Microsoft Access. A data input worksheet was created and distributed to several researchers, who then voluntarily input their information to test the functionality of this prototype database. In addition to providing their information, researchers were encouraged to return any feedback they had to help improve the database's functionality. A detailed discussion of this prototype database is provided in Chapter 4 . 


\section{Trade Space Analysis}

A trade space analysis was conducted to survey existing commercial and government tools. A trade space analysis consists of examination and evaluation of alternative ways of achieving outcomes within the context of a specific decision to be made or problem to be addressed. Using keyword searches and discussions with ERDC-CERL employees, the team found several existing tools and databases. The team performed a literature search for the commercial tools and investigated government tools to determine the advantages and disadvantages of each tool. Findings from the trade space analysis were used to influence the design and implementation of the KSA database tool.

\subsection{TIPS database}

The Technology Information, Products, and Services (TIPS) database was a legacy system developed at ERDC-CERL that was intended to capture and transfer information about ERDC-CERL's personnel, capabilities, products, and publications. Additional information about TIPS can be found in an ERDC-CERL technical report (East, Ort, and Goran 1999). Although TIPS is no longer in use, there were several advantages and disadvantages of the approach within TIPS, as outlined in subsections 3.1.1 and 3.1.2.

\subsubsection{Advantages}

The TIPS database was designed to be a comprehensive database system. The database captured a wide variety of employee inputs and was designed to allow user updates and supervisor approvals.

\subsubsection{Disadvantages}

The TIPS workflow process required supervisor approval for each individual's skills and capabilities, and those required approvals were an additional burden for supervisors. At one point, the database required researchers to input annual updates prior to their performance reviews. Although the database had great capabilities, it appears that the data entry and approval processes required to review and validate records became cumbersome for supervisors. The amount of detail and steps required to update profiles meant that the database slowly fell out of favor with re- 
searchers, and TIPS eventually was seldom used. Also, some search criteria would result in multiple identical results which made some search features less useful. For example, searching for publications would yield multiple identical results if multiple researchers had entered the same publication in their profile.

Using these findings, the KSA database tool was designed to simplify user inputs. There is currently no supervisor approval process because the tool is currently intended to be a community-level tool for ERDC-CERL employees. Several fields/inputs from the TIPS database were retained, however.

\subsection{Engineer Knowledge Online}

EKO is a knowledge management tool for USACE (Figure 2)Error! Reference source not found.. A subsection of EKO provides listings of organizations, projects, and employees. The LDP2 team focused on the employee portion of EKO to determine its advantages and disadvantages as it relates to the LDP2 goals.

\subsubsection{Advantages}

One major advantage of EKO is that it provides a list of all USACE employees. Therefore, any ERDC-CERL employee can be found in the EKO database along with basic information about their position. Additionally, the EKO search features have wide search criteria. For example, users can search by name, position, interests, projects, and several other criteria.

\subsubsection{Disadvantages}

Despite its wide reach and search criteria, the team found EKO user information to be sparsely populated. One potential reason for this lack of user data is that there are no requirements for users to upload their information. The team found that the search functionality often did not work and returned errors. So even if the information was updated, there is no guarantee that the search feature would work. The team also found some deficiencies in the fields. For example, there are no areas to enter certain individual information such as the name of a college or university and no ability to rate individual skills. 
Figure 2. Engineer Knowledge Online (EKO) home page.

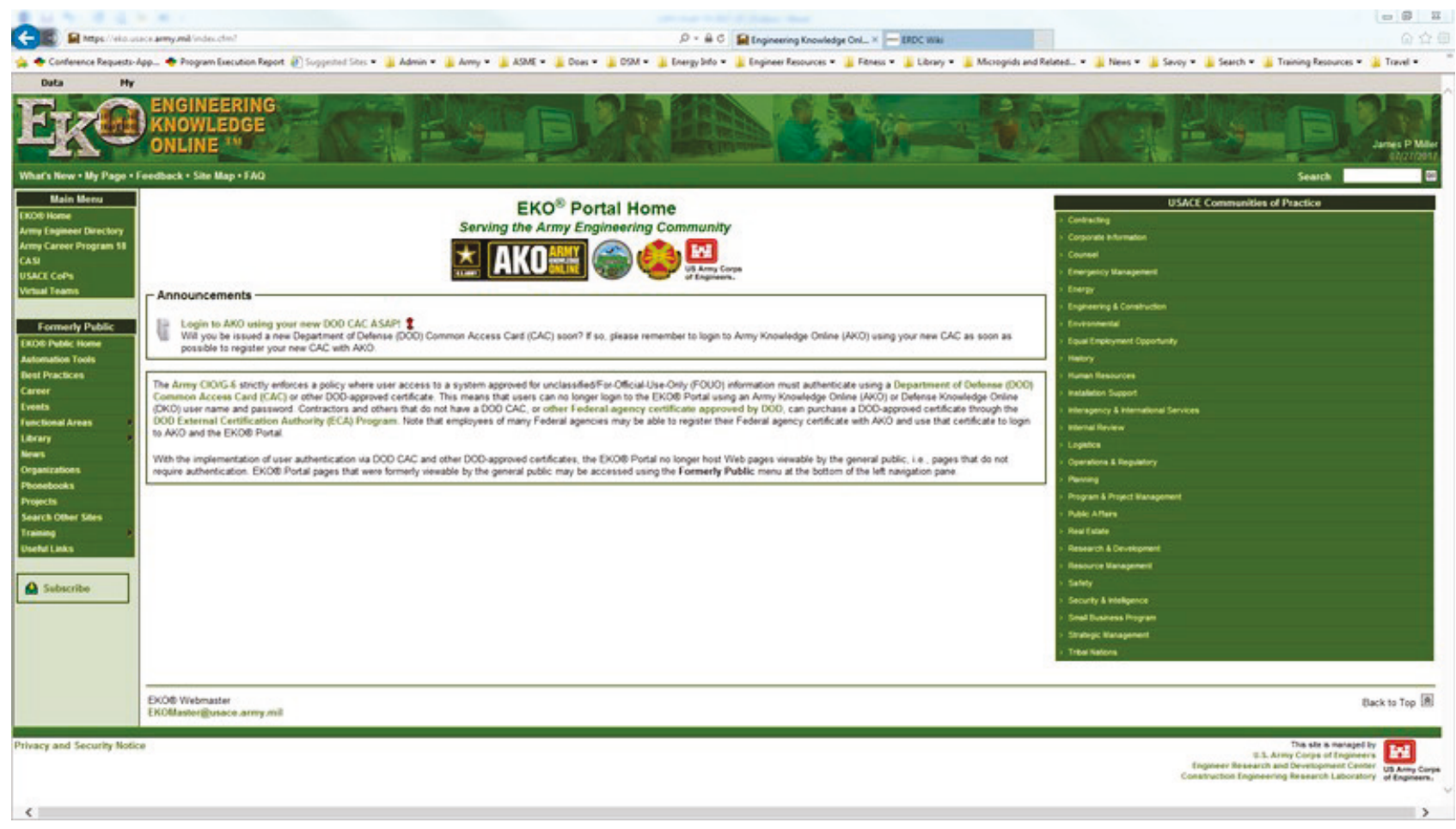

\subsection{ERDCpedia}

ERDCpedia (the "ERDC Wiki") is a public-facing website ${ }^{2}$ that informs DoD users and customers about ongoing and past ERDC projects. The website is designed like a Wikipedia page, and it lists details about ERDC projects along with point of contact (POC) information (Figure 3). ERDCpedia has some tools and capabilities that align with the LDP2 team's goals.

\subsubsection{Advantages}

ERDCpedia has a very good search function. Users can search the website with keywords that include project titles, areas of expertise, or people. The search function searches across ERDC since all ERDC labs are included, and the labs share a coordinated effort to add information to the website. Additionally, it is possible for individual researchers (through their lablevel Knowledge Management Representative) to add information as desired.

2 https://wiki.erdc.dren.mil/ERDCpedia 


\subsubsection{Disadvantages}

There are several missing features within ERDCpedia that prevent it from being used as a KSA tool. Because the pages are project-centric (and outward facing), they do not have key pieces of information that the LDP2 team desires. The pages focus on a certain subset of projects that leadership sees as the most marketable for their lab rather than on the qualifications, experience, and expertise of the people in the labs. This information includes no principal investigator (PI) information other than name and no other basic information such as contact information, skills, and qualifications. ERDCpedia's content is managed by content managers, meaning it requires an approval process for each individual contributor and the data they would enter. Since the database needs to be open to all employees (and possibly contractors) for contributing data, ERDCpedia's approval requirement would render this platform unusable for the intended purpose.

Figure 3. ERDCpedia home page.

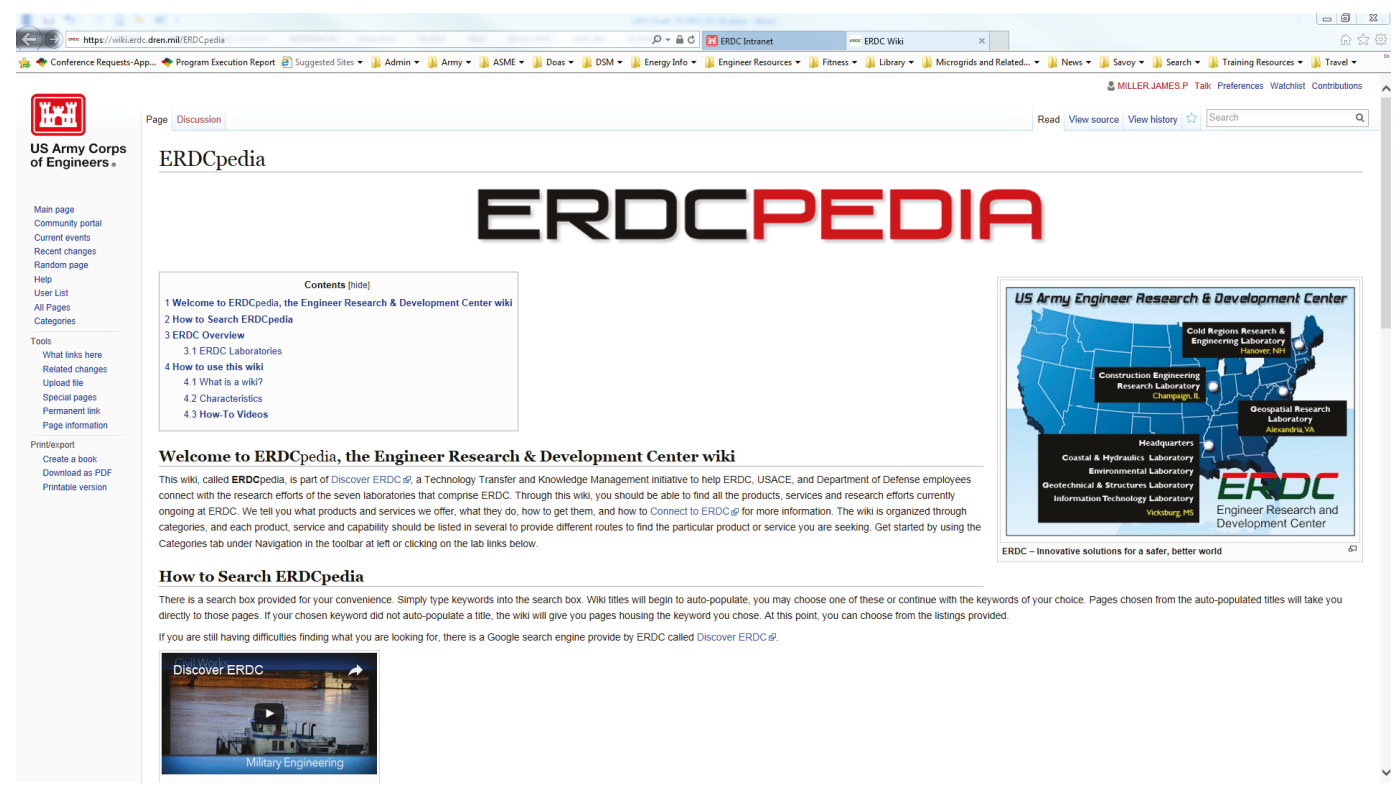

\subsection{Craig Technologies employee KSA tool}

Commercial tools were also researched as part of the trade space analysis. One tool, developed by Craig Technologies 3 is a web-based KSA tool that has very similar requirements to the LDP2 KSA database.

\footnotetext{
${ }^{3}$ Located in Cape Canaveral, Florida (www.craigtechinc.com).
} 


\subsubsection{Advantages}

The Craig Technologies KSA tool was created by using SurveyMonkey, which is a widely used and popular survey tool. The Craig Technologies website (Figure 4) had detailed instructions for using the tool, but the website is no longer operational. One advantage of their using SurveyMonkey is that data could easily be combined to provide simple analytics.

\subsubsection{Disadvantages}

A major disadvantage of the Craig Technologies tool is its use of SurveyMonkey to acquire user input data. Due to government requirements, it is difficult to create and use a website that is managed by a third party. This alone makes the use of a KSA tool based on SurveyMonkey almost impossible. Also, it appears that the Craig Technologies KSA Tool may have been intended for exclusive use within the Craig Technologies organization, making it unavailable to outside organizations.

Figure 4. Craig Technologies' employee KSA tool home page in 2017 (http://www.image-search.org/tempimgs/7387931251521149011.png).

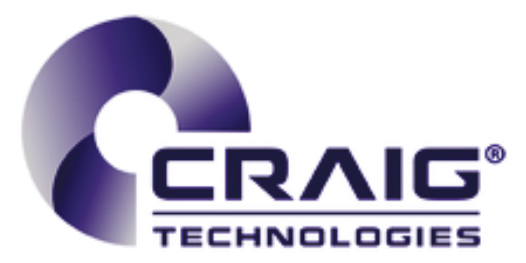

Employee Knowledge, Skills and Abilities (KSA)

\subsection{Skills DB Pro KSA tool}

Another commercial tool, Skills DB Pro (Figure 5), 4 was designed to meet an organization's skills management requirements. A review of this solution showed that the capabilities of the Skills DB Pro tool aligned very closely with the LDP2 KSA tool requirements.

\subsubsection{Advantages}

The Skills DB Pro tool provides excellent customization capabilities. Also, the tool provides in-depth analytical options that can be used to represent

\footnotetext{
${ }^{4}$ Skills DB Pro is a skills management company located in Bozeman, MT.
} 
the data in a variety of ways. Some examples are shown in Appendix A of this report. The Skills DB Pro promotional video provides a very useful snapshot of the tool's capabilities.5

\subsubsection{Disadvantages}

This is a fee-for-use tool. It is unclear whether the costs are per user or per organization. Although the tool's cost isn't necessarily a barrier to its adoption, the cost does add an increased layer of complexity in adopting the tool. More importantly, the databases and systems that manage this tool are owned by a third party. Similar to the Craig Technologies tool (section 3.4), third-party ownership poses a huge challenge in adopting this technology for government purposes.

Figure 5. Skills DB Pro home page in 2017 (https://skillsdbpro.com/).

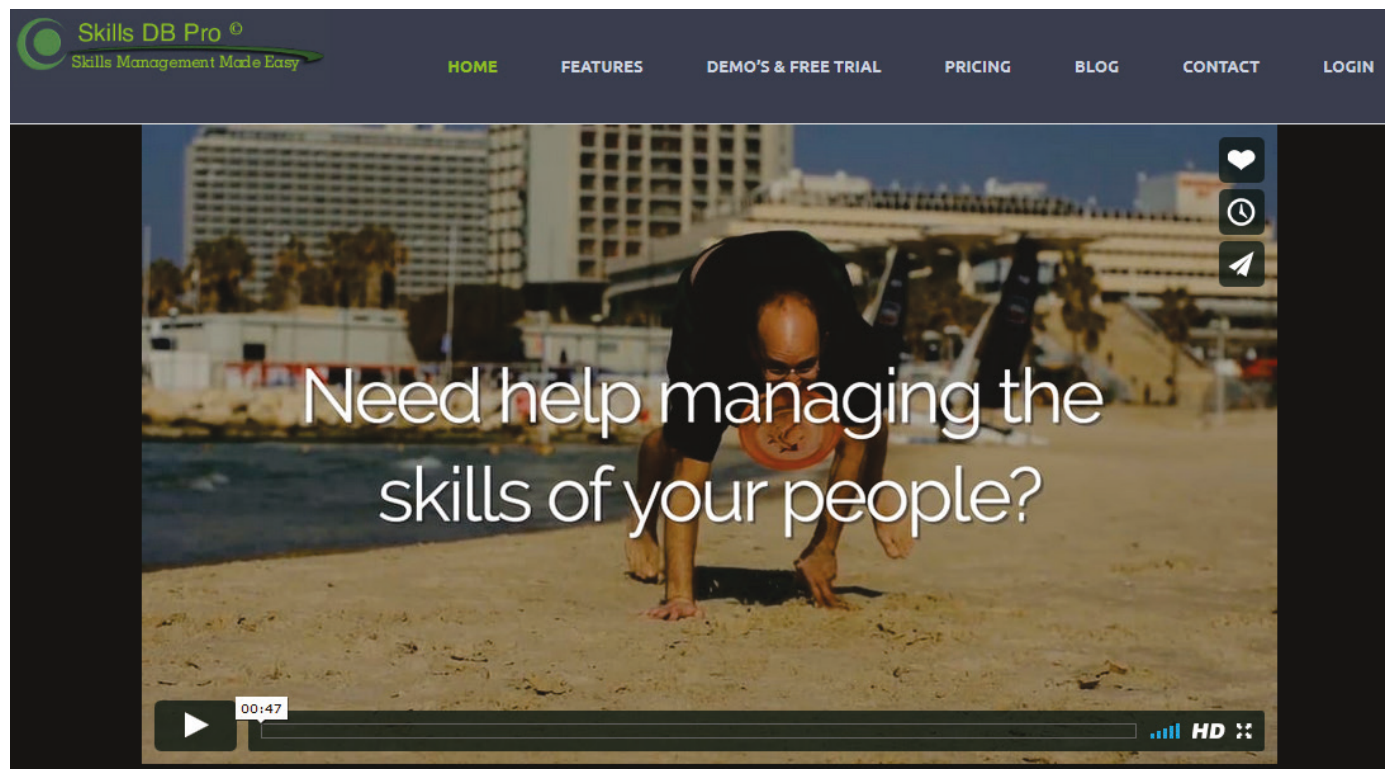

\subsection{Cold Regions Research and Engineering Laboratory initiative}

In June 2017, LDP2 team members met with Dr. Bert Davis (Chief Scientist, Geospatial Research and Engineering) of the Cold Regions Research and Engineering Laboratory (ERDC-CRREL) regarding the team's efforts to develop a KSA tool. The meeting also provided an opportunity to discuss his views on a database tool designed to promote communication and teaming within ERDC. Based on his previous experiences as a lab director and having overseen similar initiatives, Dr. Davis suggested that the data

5 http://skillsdbpro.com/demo/ 
fields incorporated into the demonstration database were appropriate for evaluating tangible skills, knowledge, and abilities but lacked a mechanism to capture nontangible qualities that could separate a good team member from a great team member. Per Dr. Davis, these nontangible qualities are "passion(s)." To gather data on passions, he suggested that a field for nondiscrete biographical write-ups be incorporated into the profile data. Although a text box large enough to capture biographical information would not be searchable in an initial data query, once a potential field of candidate project team members was narrowed down, the information could greatly benefit final selection decisions.

Dr. Davis also suggested the team talk with ERDC-CRREL researchers who had worked to develop a KSA tool as part of their funded 2016 ERDC Innovation Alley project, "Increasing Collaboration with an Intuitive Researcher Directory." The project's objective was to develop a directory containing abridged employee biographies and a project message board to enhance interpersonal communication across the laboratory and provide a resource for allocating employee hours and skill sets. We spoke with team members Dr. Matthew Parno and Ms. Samantha Sinclair, who directed the ERDC-CERL team members to a link for their KSA tool, which is hosted on the ERDC Research and Development Enterprise (RDE) network. ${ }^{6} \mathrm{~A}$ screen capture of the opening page is shown in Figure 6.

One can see from Figure 6 that the ERDC-CRREL team apparently intended their tool to be ultimately available to and used by each of the ERDC labs and the ERDC organization as a whole. Currently, while a significant number of ERDC-CRREL researchers have populated their employee profiles (Figure 7), only one researcher from a different lab, the Information Technology Laboratory (ERDC-ITL), has done the same.

${ }^{6}$ http://rde-gpu/directory/ 
Figure 6. Opening page of the CRREL KSA tool (http://rde-gpu/directory/).

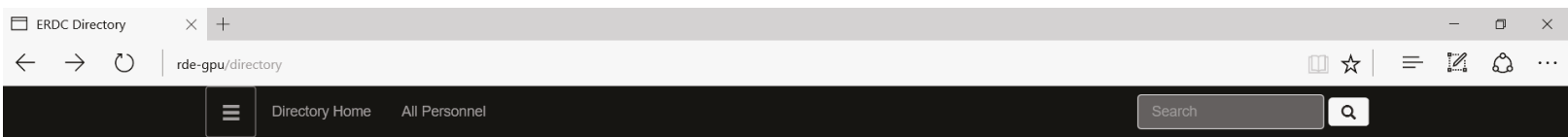

Browse Personnel by Lab

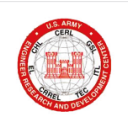

ERDC

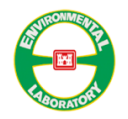

EL

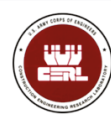

CERL

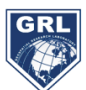

GRL

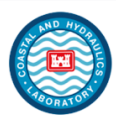

$\mathrm{CHL}$

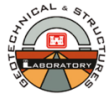

GSL

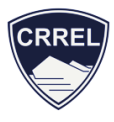

CRREL

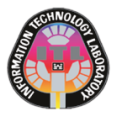

ITL

Figure 7. Examples of employee profile data fields in the ERDC-CRREL KSA tool.

\section{ERDC Personnel}

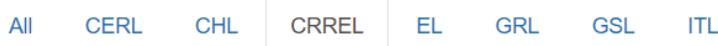

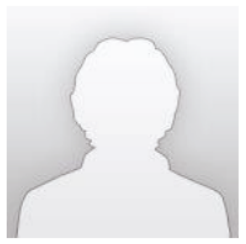

Sam Baldwin

Computer Scientist

(CRREL-RSGIS)

samuel.g.baldwin@erdc.dren.mil

(603) 348-0495

Interests:

Skills:

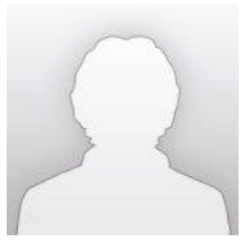

Samuel Beal

Research Chemist

(CRREL-BSB)

samuel.a.beal@erdc.dren.mil

(603) $646-4125$

Interests:

Energetic compounds, heavy metals , mercury , particulate matter , limnology , ice cores

Skills:

HPLC , GC , IC , ICP-OES , SEM , R , Writing and Editing 
Figure 7 shows that the tool includes fields for:

- employee picture,

- employee name,

- job title,

- organization,

- email address,

- phone number,

- interests, and

- skills.

As seen in Figure 7, some employees have attempted to populate most of the data fields in their profiles, while others (to date) have not. The Email Address field shown in the employee profiles is active, so one can click on the address and initiate an email to the employee of interest. The Phone Number field, however, is not active. Clicking on a Phone Number field results in a popup stating that an app is required to initiate a phone call. For security reasons, the necessary app is not being made available.

Clicking on a Job Title field in the ERDC-CRREL KSA tool results in listings of all employees having that job title, as shown in Error! Reference source not found. and Error! Reference source not found.. Clicking on the left side of the Organization field results in a listing of all employees within that particular laboratory. Clicking on the right side of the Organization field will list all employees within the given sub-organization.

Figure 8. Search results for all employees currently listed as "Computer Scientist."

\section{Results for search: "Computer Scientist"}

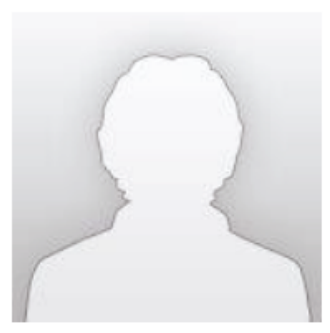

Sam Baldwin

Computer Scientist

(CRREL-RSGIS)

samuel.g.baldwin@erdc.dren.mil

(603) 348-0495

Interests:

Skills: 
Figure 9. Partial search results - employees currently listed as "Research Physical Scientist."

\section{Results for search: "Research Physical Scientist"}

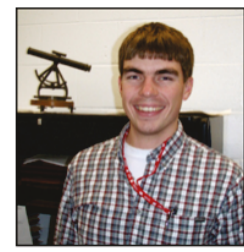

\section{Matthew Parno}

Research Physical Scientist

(CRREL-TCSB)

matthew.d.parno@erdc.dren.mil

(603) $646-4148$

Interests:

Bayesian Statistics, Uncertainty Quantification, Inverse Problems, Markov chain Monte Carlo (MCMC), Data Assimilation, Discrete Element Methods (DEM), Finite Element Methods (FEM), Numerical Modeling

Skills:

$\mathrm{C}^{++}$, Python , High Performance Computing (HPC), LaTeX, Fortran, Soldering

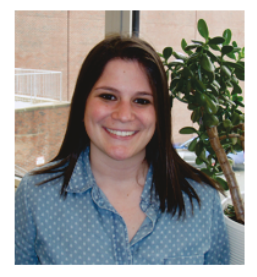

Samantha Sinclair

Research Physical Scientist

(CRREL-TCSB)

samantha.n.sinclair@erdc.dren.mil

(603) 646-4164

Interests:

Geology, Geomorphology , Geophysics, Glacial Geology , Sedimentology , Climate Change , Remote Sensing

Skills:

ArcGIS , Ground-Penetrating Radar , LiDAR, GPS , Fieldwork

Clicking on entries in the Interests field will result in a listing of all employees having the same entry in either their entry's Interests field or Skills field. Likewise, clicking on entries in the Skills field will result in a listing of all employees having the same entry in either their Skills field or Interests field.

It appears that the individual data entries for the Job Title, Organization (Lab and Sub-organization), Interests, and Skills fields are selected from pick lists in order to maintain consistency and avoid spelling errors, both of which are necessary to assure that these fields will be searchable). A downside of using pick lists, especially for the fields of Interests and Skills, is that it can become burdensome to maintain pick lists with all possible interests and skills that a user might wish to select. Additionally, users might be frustrated to find that a particular Interest or Skill they wish to select is not included in current versions of the pick lists. 


\section{Data}

\subsection{Data to be captured}

ERDC-CRREL's KSA tool does a good job of cataloging and documenting basic employee information in an easily searchable format. However, the team wants to expand the proposed ERDC-CERL database to capture additional information beyond the scope of the ERDC-CRREL tool.

Data to be included in ERDC-CERL's KSA tool should encompass aspects of each employee's knowledge, skills, and abilities, as well as their contact information and demonstrated expertise. This data includes basic, professional, and educational information, as well as professional affiliations, publications, awards and honors, and other skills.

This chapter documents the fields, sources, and rationale for the data included in our prototype database. The chapter is divided into sections and subsections that describe categories of data fields, data fields within each category, and the rationale for their inclusion. Unique data field values (e. g., last name, phone number) are direct entry. Many other variables are discrete and searchable. For example, data fields that are common among individuals, but may be entered in multiple formats (e. g., degree, job title, etc.), were included as picklists.

The process for determining what fields to incorporate into the demonstration database was largely based on the intent of the database-to provide a tool for researchers and other ERDC-CERL staff to identify project partners and opportunities. Given this as its mission, the LDP2 team collaborated within the team and enlisted the input of branches and interested individuals to compile a list of relevant data fields. Data identification sessions were held during LDP2 team meetings, branch meetings, and RForum discussions.

Finally, suggestions for data fields not currently included in the demonstration database are highlighted in the last subsection of this chapter. 


\subsubsection{Contact information}

These fields represent contact information that provides general background and information on an individual. WARNING: These fields provide the greatest risk for mishandling of PII.

- Last Name [Unique]

- First Name [Unique]

- Middle Name [Unique]

- Prefix [Pick List]

- Suffix [Pick List]

- Phone [Unique]

- Email [Unique]

- Branch [Pick List]

- Job Series [Pick List]

- Job Title [Pick List]

- Function Title [Unique]

- Years [Unique]

- Veteran $(\mathrm{Y} / \mathrm{N})$ [Pick List]

\subsubsection{Military service}

- Service [Pick List]

- Branch [Pick List]

- Service Start Date [Unique]

- Service End Date [Unique]

- Rank Type [Pick List]

- Rank Number [Pick List]

\subsubsection{Project background}

These fields represent information needed to determine the level of experience and interactions with reimbursable customers. These fields are useful for identifying potential team members based on marketing and other non-technical skills.

- Focus Area [Unique]

- Customers [Unique] 


\subsubsection{Education}

The intent of these fields is to provide information on the educational background of a potential team member. The fields include the following:

- Degree Type [Pick List]

- Degree Major [Pick List]

- Degree Year [Unique]

- Degree School [Unique]

\subsubsection{Skills/Professional Licenses}

Fields in this section capture an individual's knowledge and abilities with both hardware and software tools. Academic education often defines the core of individual competencies; however, competency with computer software/hardware, discipline-specific technical tools (e.g., global positioning software [GPS]) is often developed with time and experience. This section provides a means to catalog and identify proficiencies in these areas.

- License Title [Pick List].

- License State [Pick List]

- License Year [Unique]

- Areas of Expertise [Unique]

- Professional Organization [Unique]

- Professional Organization Office Held [Pick List]

- Date Office Held [Unique]

- Software Experience [Unique]

- Software Type [Unique]

- Software Proficiency Level [Pick List]

- Software Certification [Unique]

- Hardware Instrument Name [Unique]

- Hardware Type [Unique]

- Hardware Proficiency [Pick List]

- Hardware Certification [Unique]

- Other Professional Certifications [Unique]

- Certifying Organization [Unique] 


\subsubsection{Publications}

These fields capture an individual's written achievements. They are designed to capture both peer-reviewed publications (journal articles, etc.); along with non-peer-reviewed technical publications (ERDC and cross agency technical documents). Publications are important to ERDC-CERL researchers as they provide insight into an individual's technical knowledge, technology transfer achievements, and written communication skills.

- Publication Type [Unique]

- Publication source [Unique]

- Title [Unique]

- Year Published [Unique]

- Volume [Unique]

- First Page [Unique]

- Last Page [Unique]

- First Author's Last Name [Unique]

- First Author's Initials [Unique]

- Second Author's Last Name [Unique]

- Second Author's Initials [Unique]

- Third Author's Last Name [Unique]

- Third Author's Initials [Unique]

- Other Authors [Unique]

\subsubsection{Currently missing data/fields}

The fields and groupings listed above are not exhaustive. Fields not present are functional parameters such as data record indices that are integral to the design and function of data organization and manipulation in the software database.

Additionally, fields for administrative function and maintenance of the database were discussed, but they were not incorporated into the prototype database tool. These include fields that track when data records were entered and/or last updated.

\subsection{Data ownership}

The primary responsibility for populating and updating data should fall on individual employees. The team hopes that the benefits of showcasing 
strengths and experiences to foster collaboration should be a strongenough incentive for maintaining up-to-date information. First-line supervisors should encourage participation through incentives, such as encouraging or requiring updated information for use in determining performance scores, as has been done in the past. Adding new entries as part of new employee checklists will encourage employee data ownership over time, as participation becomes a matter of habit.

\subsection{Data validation}

Maintaining accurate and updated information will be key to sustaining a useful tool. A "Last Updated" feature will allow users to see if information on specific pages is up to date or lapsed. First-line supervisors should, at their discretion, review all entries and updates to ensure the validity of data and to clarify any unclear entries.

\subsection{PII issues and concerns}

To minimize or avoid PII issues, we suggest the following requirements:

- Individual employees will have read/write/modify/delete access to their own records via CAC login so that they can control their own data. Other employees who wish to peruse the database will also log in via CAC, but they will have read-only access to other employees' records.

- The database will be hosted on a government server, and that server will not be available outside of ERDC-CERL or ERDC networks.

- Personal information such as age, birthdate, birthplace, home address, are irrelevant to the purpose of this database and are not to be recorded. 


\section{Database}

\subsection{Data structures}

As stated earlier, the demonstration database was created in Microsoft Access. Access database software was chosen because it is installed on all ERDC-CERL employees' computers, is compatible with Microsoft SharePoint, and will be used to capture employee data at a relatively small site (ERDC-CERL). It provides a good platform for collecting data easily and testing aspects of the database architecture.

The framework was created first, which is represented by Figure 10.

Figure 10. Architectural framework for the ERDC-CERL KSA tool.

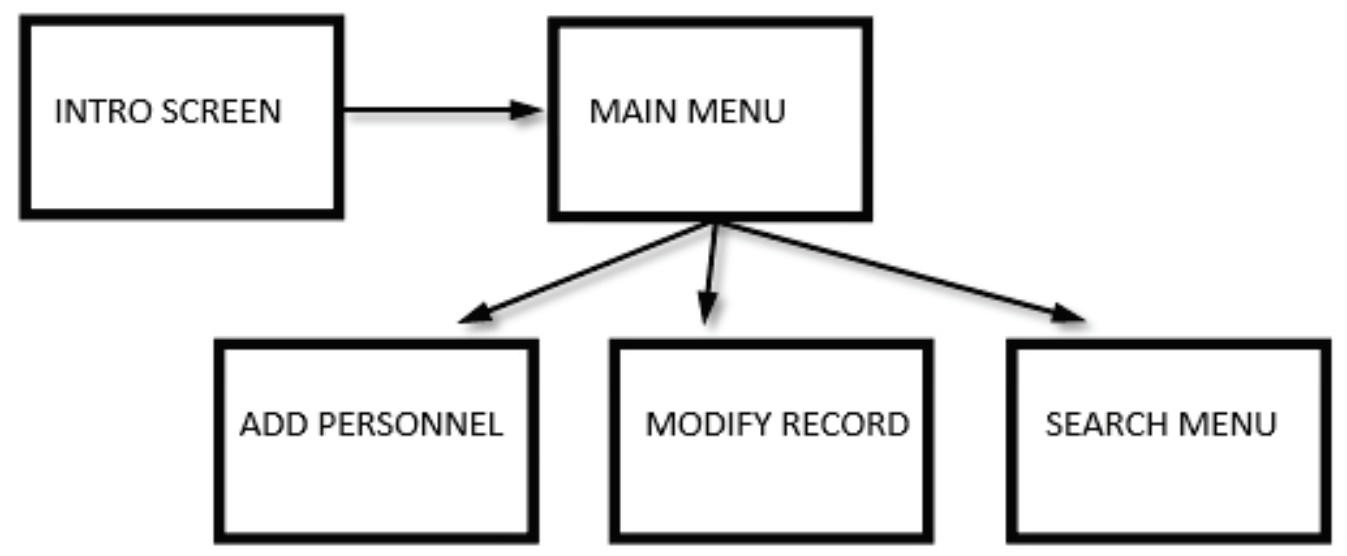

The main table within the database is the Personnel Table, a portion of which is shown in Figure 11. It contains all of the individual's information, and it links with other tables for information that might be redundant or shared with other individuals. Other tables include Prefix, Branch, Job Series, Degree Type, Degree Name, Licenses, State of Licensure, Software Proficiency, and Hardware Proficiency.

One issue that arose in building this database involved the search capability of multiple acquisitions. As an example, consider college degrees. The database stores each Degree Type, Degree Name, Graduation Year, and Institution from which it was obtained. If a person has two degrees, then the information in each of these fields has to be linked to the correct degree. To accommodate this requirement, the database includes the ability for each individual to store five separate degrees, along with pertinent information. In the chart below (Figure 11), therefore, can be found Degree1, 
Degree2, DegreeType1, DegreeType2, etc. This separation makes the information searchable.

A free-form text box has been provided for AreasofExpertise. This text box allows the user to type in anything that he/she considers an area of expertise. It allows the greatest freedom to the user, but that freedom could reduce searchability. Although this field is searchable, any misspellings could cause a failure of the data to be found by a search.

Figure 11. Sample of database architecture for ERDC-CERL KSA database.

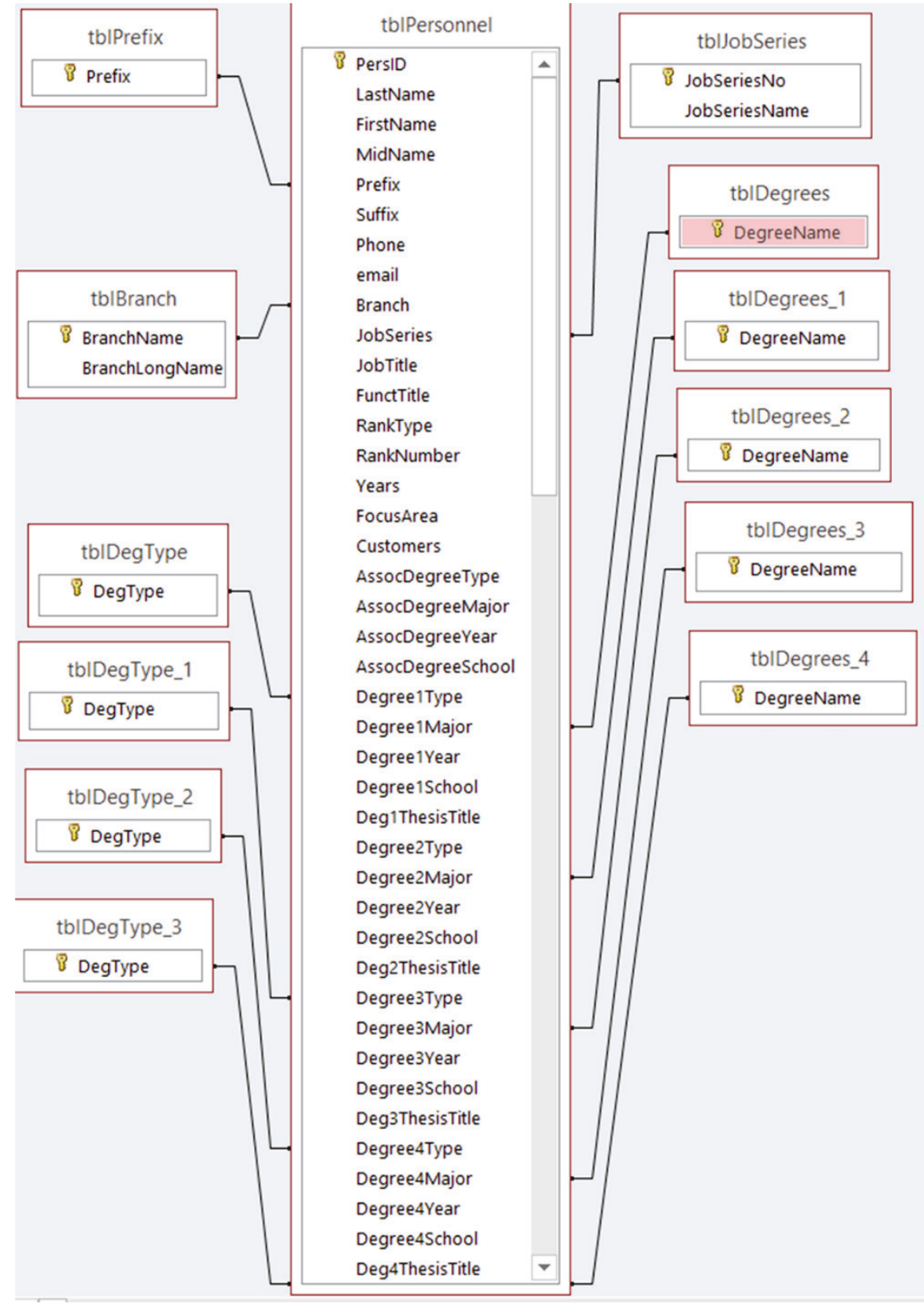




\subsection{Development and refinement}

As indicated above, the database has a Main Menu (shown in Figure 12). The three black-labeled buttons on the left side of the figure have been developed and are currently active. The two red-labeled buttons on the right are potential functions that have not yet been developed but should be considered during refinement and further development of this database. Each of the developed functions is described in 5.2.1.

Figure 12. Main menu page of ERDC-CERL's “ASK CERL” KSA database.

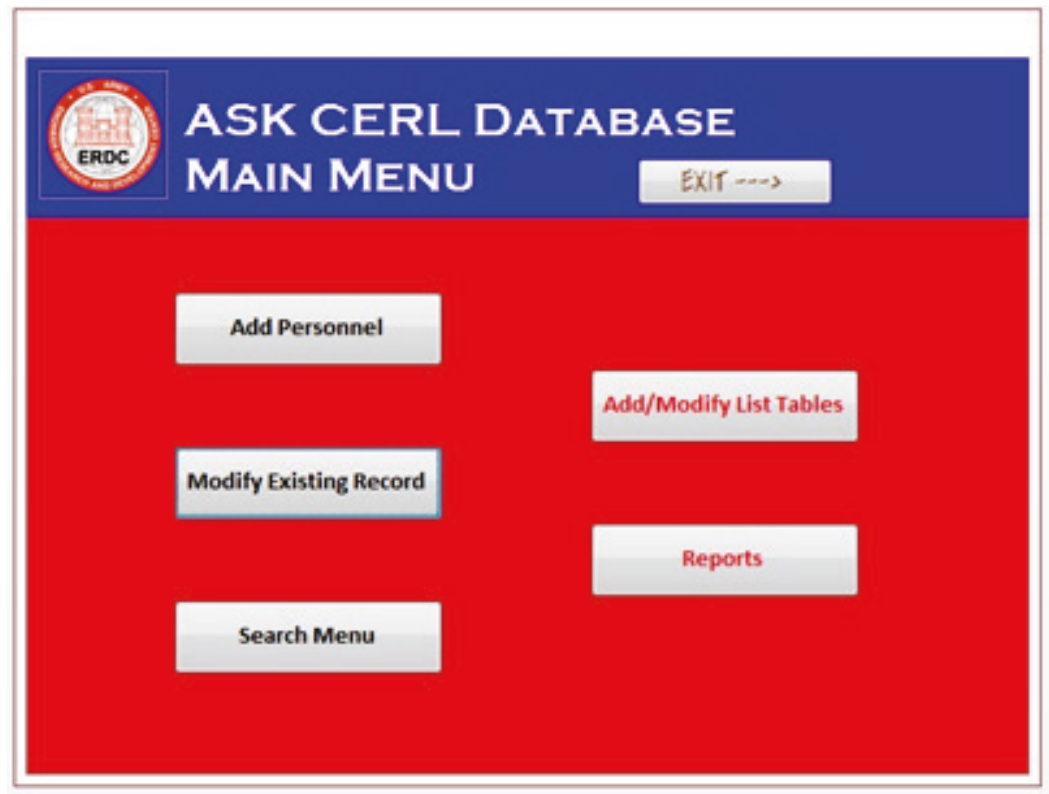

\subsubsection{Add Personnel form}

A form was created for individuals to initiate and input data into their own profile. Selecting "Add Personnel" takes the user to the input form shown in Figure 13 and brings up a blank form for a new record. Some of the fields (e. g., First Name) are freeform text. The user can input whatever information is needed into these freeform text fields. Other fields were created as drop-down menus (e. g., Degree Type and Degree Name). Fields that are intended to be searchable were chosen to have drop-down menus. By having a table of values from which the user makes a selection, spelling errors are eliminated and the values entered into the user's record are then assured to be searchable. 
Figure 13. The Add Personnel data input form.

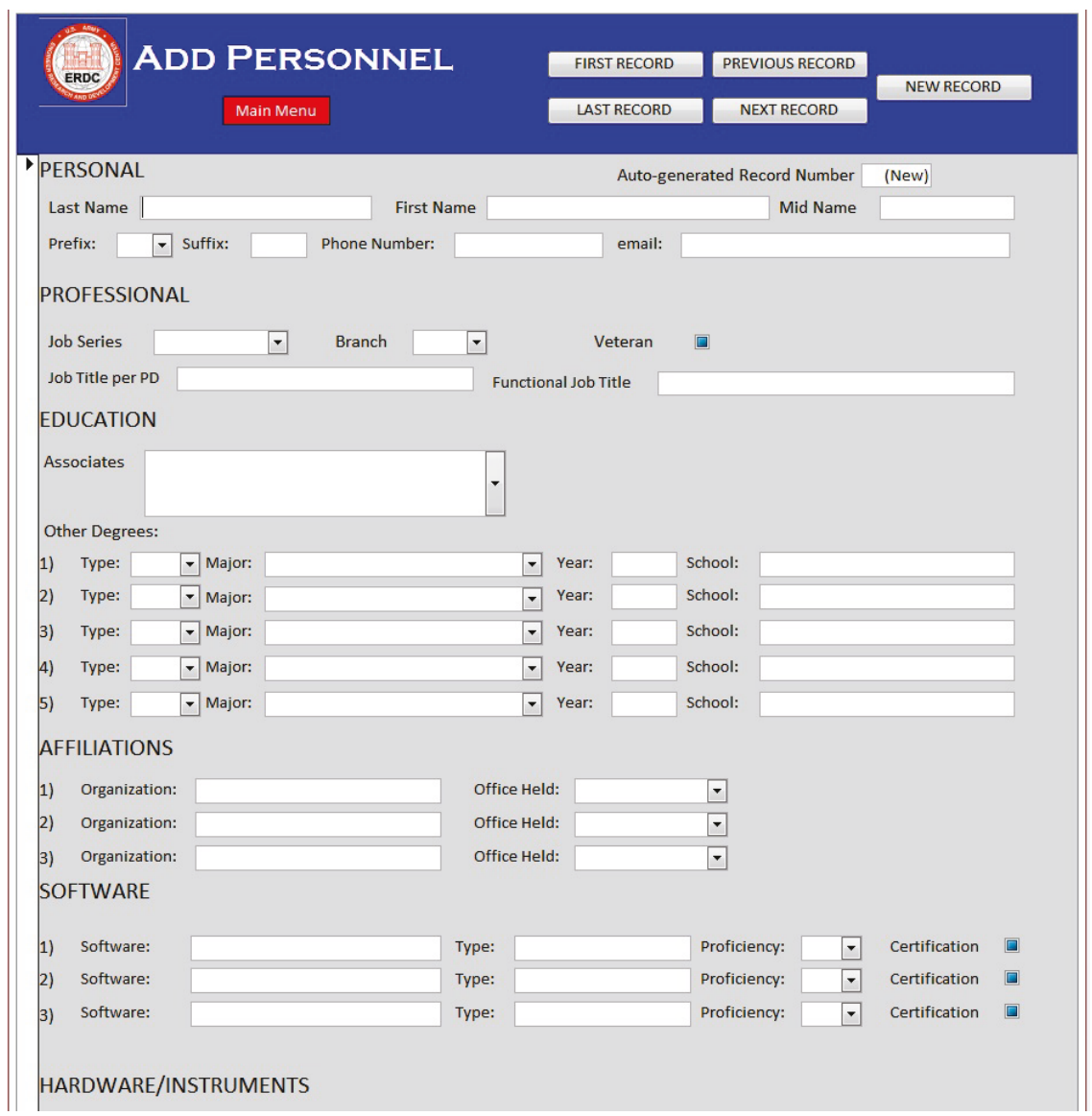

\subsubsection{Modify Existing Record form}

Selecting "Modify Existing Record" takes the user to a similar input form (Figure 14), with the difference being that this form has a search window so that the user can search for a particular record to modify. 
Figure 14. The Modify Personnel data input screen.

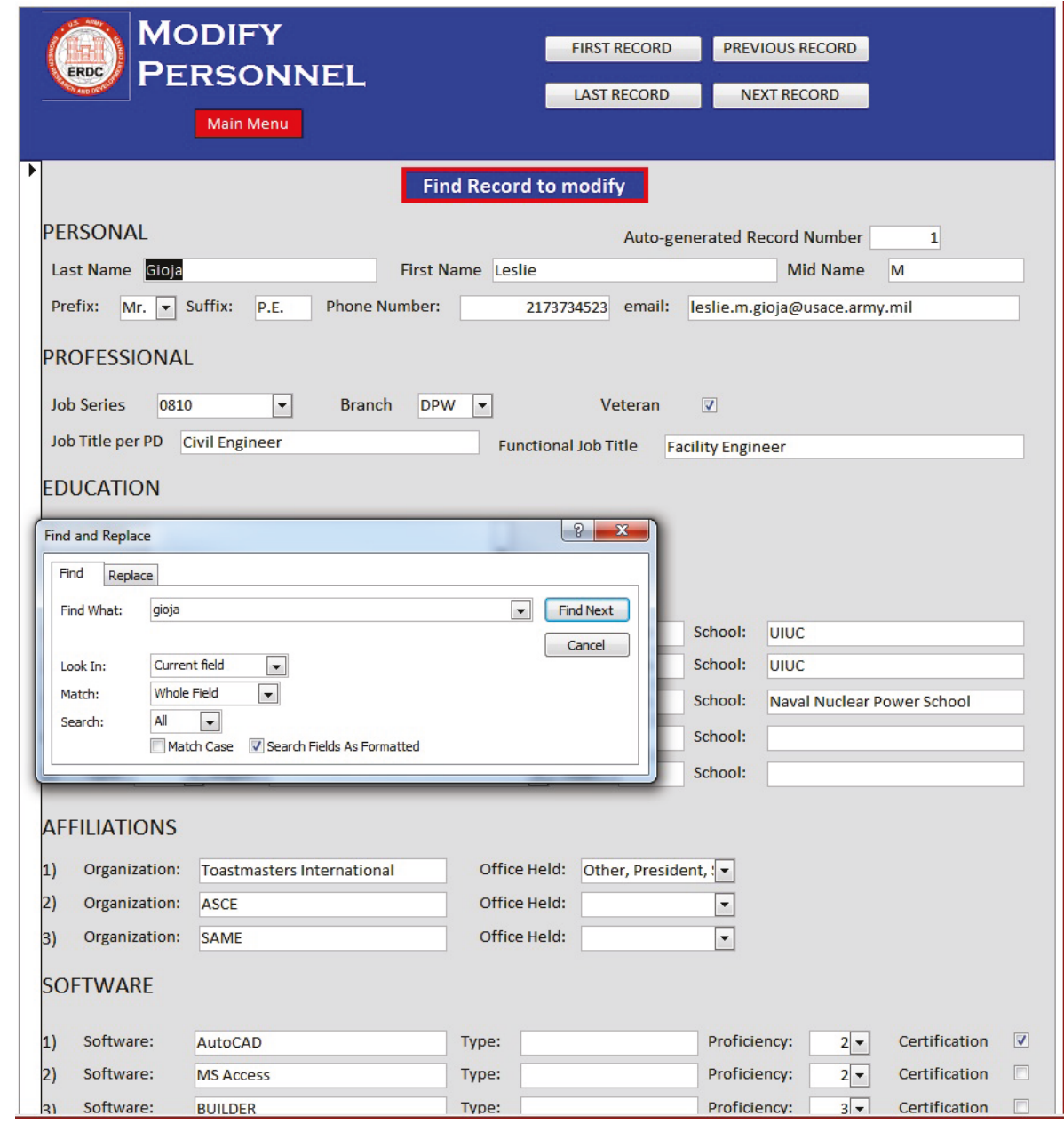

\subsubsection{Search menu}

Selecting the button "Search Menu" opens a menu (Figure 15) from which the user can select from various types of searches. All searches are set up to search for a part of the word that was entered to be searched. This partial word search feature can help the user in at least the following three ways: (1) to find a name, even if unsure of its complete spelling; (2) to find something more easily that has been mistyped; and (3) to search for an entire group of engineering majors or specialties by typing "eng" or "engineering" in the search box.

The following searches are currently active: Last Name, First Name, Degree, Area of Expertise, and Branch. Others could be added. 
Figure 15. The Report Search Menu screen.

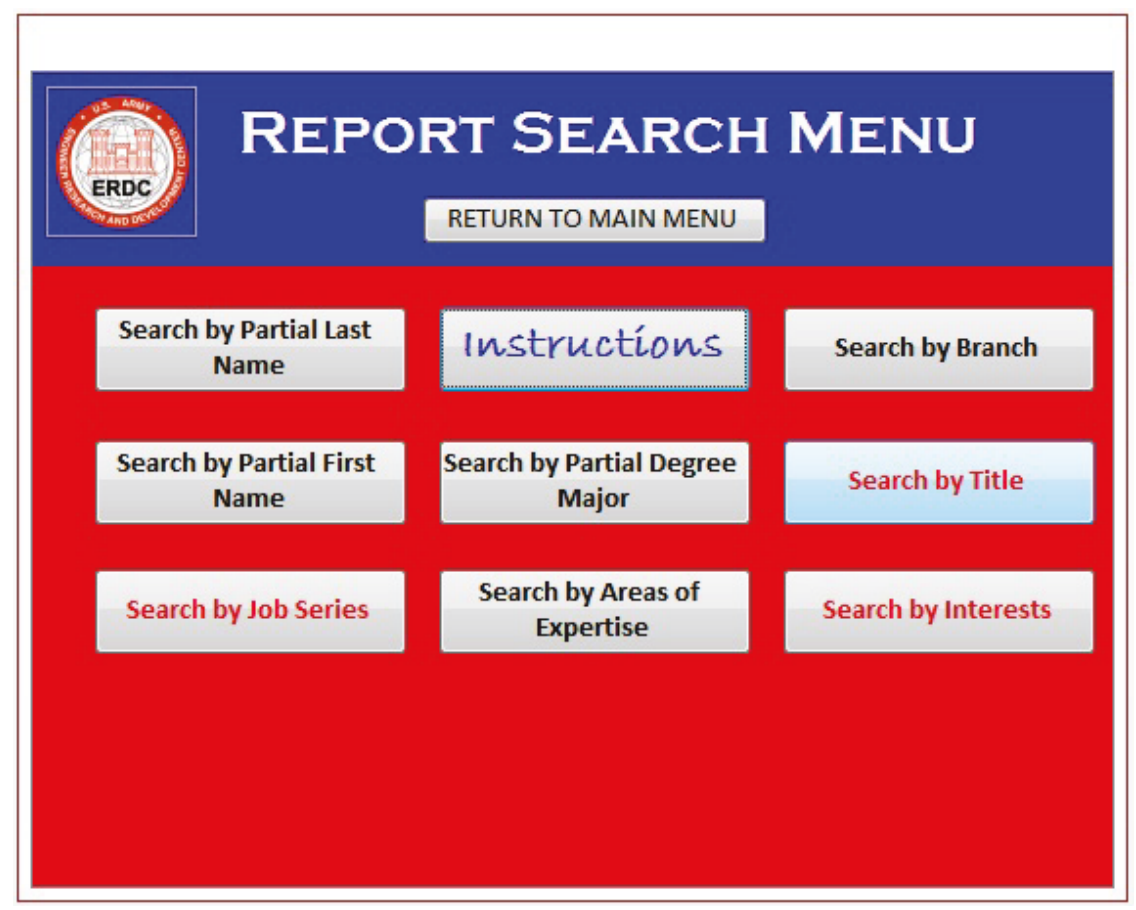

Searching by Name will bring up a box requesting the name to be searched, as shown in Figure 16. Figure 17 shows the search results.

Figure 16. Partial Name search entry screen.

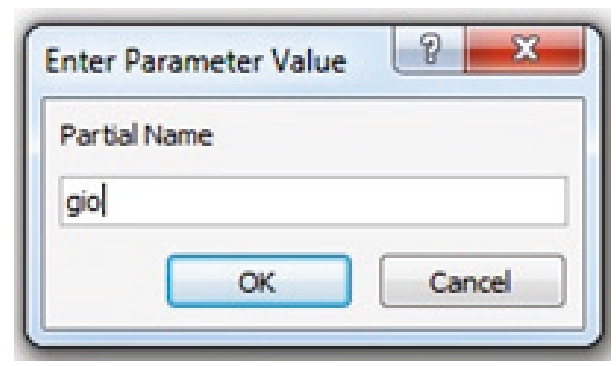

Figure 17. Search by Last Name results screen.

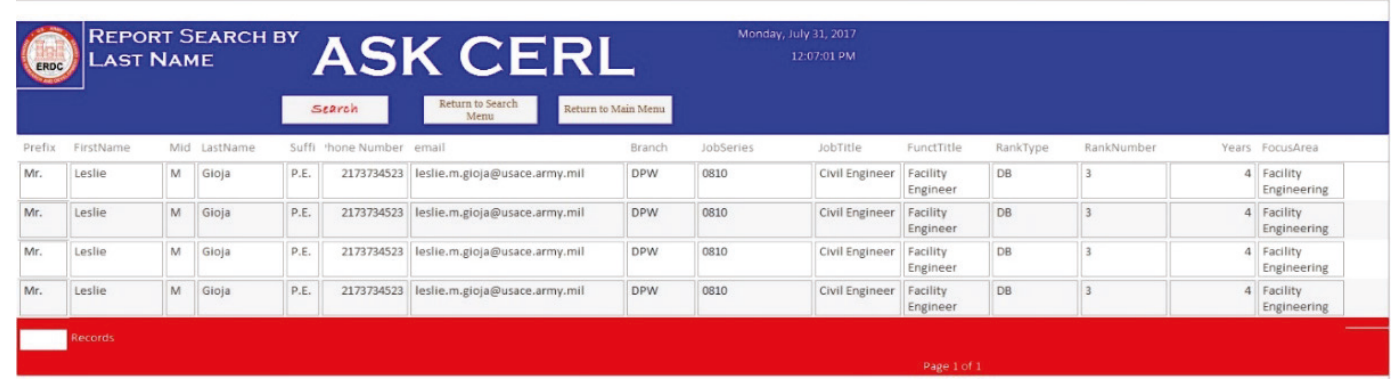


Once the report is visible, it can be printed. Also, from this page the user can choose to search again, return to the Search menu, or return to the Main menu.

\subsection{Initial data population}

The database was first populated with the LDP2 team's information. Input forms and data searchability were tested during this step. A number of programming bugs were identified and corrected. Subsequently, the database was posted on SharePoint, and employees from four ERDC-CERL branches were invited to input data. The database currently has 24 entries. The data entry page has proven to be robust and relatively easy to use.

\subsection{Hosting}

The database is currently posted on SharePoint. Although the database could be moved to the RDE network, it may be best to keep it on SharePoint since many ERDC-CERL employees do not have access to the RDE network.

\subsection{Security issues}

We believe that security issues should be minimal since this database will be hosted on a government server and will require CAC login to access it. Also, the system incorporates no means of exporting or printing data records.

\subsection{Maintenance}

Initially it is anticipated that software bugs and some functional issues will be encountered. Initial deployment will probably require a total of a couple of days' time during the first year for a skilled database developer to address the bugs and functional issues.

The need for maintenance of pick lists is also anticipated as employees identify and request the addition of data entries not available in current pick lists. This need is expected to require a few hours per year for a minimally skilled employee. 


\section{Recommendations}

\subsection{Pre-deployment refinement}

The KSA tool is presently not ready for deployment to the workforce. Further refinements are needed, such as:

- Since the LDP2 team had limited database development skills, Microsoft Access was used (software for which team members had at least workable skill levels). In order to roll out this tool to the entire ERDCCERL workforce, it might be necessary to implement this tool in a more robust database application.

- A number of buttons on the Main Menu are currently not functional; these need to be activated.

- CAC accessibility and appropriate permissions need to be set up.

Following these refinements, a period of beta testing should be planned, to make sure that bugs are detected and corrected in the database prior to rolling it out to the entire workforce.

\subsection{Hosting}

It is anticipated that this tool can continue to be hosted on ERDC-CERL's SharePoint site.

\subsection{Ownership of the KSA tool}

To be most effective, ERDC-CERL's KSA tool should be a voluntary tool and not a requirement. It needs to satisfy the interests and needs of the workforce and provide value to them. To do that, ownership of the tool should be given to representatives of the workforce, possibly the RForum. The owners could solicit feedback from the workforce regarding enhancements and improvements. Being responsive to employees' ideas or suggestions would immediately distinguish the ERDC-CERL KSA tool from other enterprise systems (such as CEFMS) which are seen as very unresponsive to employee suggestions.

\subsection{Further development and maintenance of the KSA tool}

Initial deployment and implementing further enhancements will require specialized software development skills because this is a software tool. A 
small amount of labor funding, as estimated in Chapter 1, is suggested to be budgeted to complete this work. A week of a skilled database developer's time to get this tool ready for initial deployment to the workforce, along with approximately two days of a skilled database developer's time to do annual updates and refinements should be adequate. 


\section{References}

East, William, Sara E. Ort, and William D. Goran. 1999. Providing Technology Information, Products, and Services (TIPS) Through the World Wide Web. ERDC-CERL Technical Report 99/80. Champaign, IL: Construction Engineering Research Laboratory. 


\section{Appendix A: Skills DB Pro KSA Tool}

The images below show various snippets of images from the Skills DB Pro KSA tool.
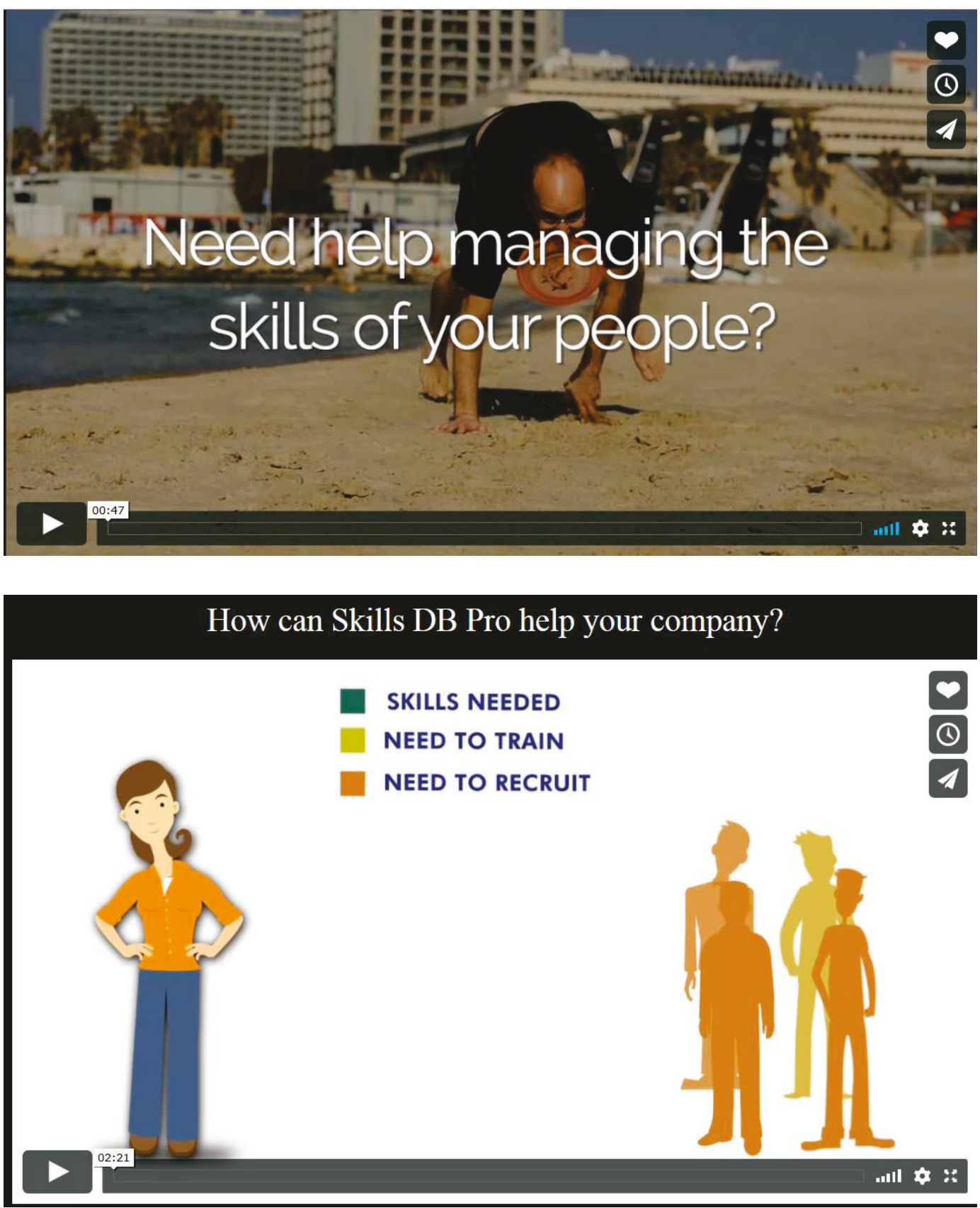
Skills DB Pro provides the answers you need.

In Skills DB Pro your data is easy to search and analyze, giving you insights to your most common and troublesome questions.

Find me our C\# Programmers with knowledge of .Net, Ajax, SQL Server and JavaScript?

Is our focus and investment in skills training aligned with our business goals and objectives?

What are our core competencies?

How can I create a Skills Matrix?

Employee evaluations are coming up, how can I discuss employee skill levels objectively?

What skills do I need to be successful in my current and or future job?

\section{Powerful \& Simple to Use}

From training needs analysis, to project placement, to employee reviews, Skills DB Pro is the refreshingly simple skills tracker. No more spreadsheets, sticky notes, and emails about who has what skills, just one uncomplicated, central hub. 


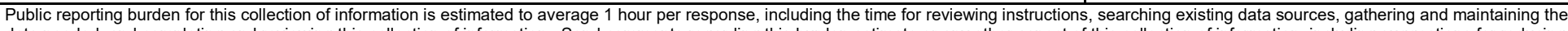

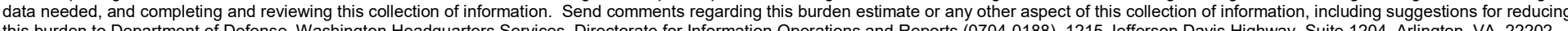

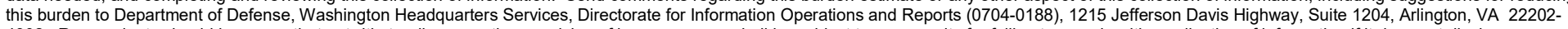

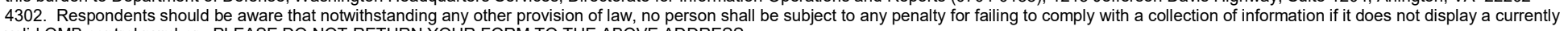
valid OMB control number. PLEASE DO NOT RETURN YOUR FORM TO THE ABOVE ADDRESS.
1. REPORT DATE (DD-MM-YYYY) May 2018

\section{REPORT TYPE}

\section{Final}
3. DATES COVERED (From - To)

4. TITLE AND SUBTITLE

A Proposed Knowledge, Skills, and Abilities (KSA) Database Tool for ERDC-CERL

5a. CONTRACT NUMBER

5b. GRANT NUMBER

5c. PROGRAM ELEMENT NUMBER

Ryan R. Busby, Donna R. Cockburn, Leslie M. Gioja, Patrick J. Guertin, James P. Miller, and Tapan C. Patel

7. PERFORMING ORGANIZATION NAME(S) AND ADDRESS(ES)
U.S. Army Engineer Research and Development Center (ERDC)

Construction Engineering Research Laboratory (ERDC-CERL)

PO Box 9005

Champaign, IL 61826-9005

\section{SPONSORING / MONITORING AGENCY NAME(S) AND ADDRESS(ES)}

U.S. Army Engineer Research and Development Center

3909 Halls Ferry Road

Vicksburg, MS 39180 ERDC

\section{DISTRIBUTION / AVAILABILITY STATEMENT}

Approved for public release. Distribution is unlimited.

\section{SUPPLEMENTARY NOTES}

\section{ABSTRACT}

Since the Engineer Research and Development Center's Construction Engineering Research Laboratory (ERDC-CERL) operates within a relatively fast-paced business world, often with short and rigid execution schedules, researchers need to quickly assemble effective teams with the right knowledge, skills, and abilities (KSAs) to timely complete high-quality work. Persons within ERDC-CERL may have the needed KSAs, but locating them currently and quickly can be challenging.

ERDC-CERL's FY17 Level II Leadership Development Program (LDP2) team recommends addressing the lack of a central repository for ERDC-CERL employees' KSAs, because lack of such information often leads to outsourcing and missed opportunities for in-house teaming among ERDC-CERL personnel. After considering a number of ideas, the LDP2 team developed a database that would enable ERDC-CERL employees to document their unique capabilities and qualifications, and it would also enable project managers, researchers, and others to search the database for persons with KSAs that could be useful on future project teams.

The team's concept is compared to past and present ERDC tools and to commercially available KSA database tools. The team concludes that its database concept is superior, but it also identifies needed refinements be-fore laboratory-wide deployment.

\section{SUBJECT TERMS}

Human capital-Management, Personnel management, Knowledge workers, Knowledge management, Intellectual capital, Databases

\section{SECURITY CLASSIFICATION OF:}

\section{a. REPORT}

Unclassified

\section{b. ABSTRACT}

Unclassified

\begin{tabular}{|c|}
$\begin{array}{l}\text { 17. LIMITATION } \\
\text { OF ABSTRACT } \\
\text { UU }\end{array}$ \\
\end{tabular}

\begin{tabular}{l|} 
18. NUMBER \\
OF PAGES
\end{tabular}

5d. PROJECT NUMBER
5e. TASK NUMBER
FY17 LDP2
5f. WORK UNIT NUMBER
8. PERFORMING ORGANIZATION REPORT
NUMBER
ERDC-CERL SR-18-2
KSA database tools. The team concludes
ERDC
ERONSOR/MONITOR'S ACRONYM(S)
11. SPONSOR/MONITOR'S REPORT
NUMBER(S)
FY17 LDP2 NUMBER 5d. PROJECT NUMBER
5e. TASK NUMBER
FY17 LDP2
5f. WORK UNIT NUMBER
8. PERFORMING ORGANIZATION REPORT
NUMBER
ERDC-CERL SR-18-2
KSA database tools. The team concludes
ERDC
ERONSOR/MONITOR'S ACRONYM(S)
11. SPONSOR/MONITOR'S REPORT
NUMBER(S)

5d. PROJECT NUMBER
5e. TASK NUMBER
FY17 LDP2
5f. WORK UNIT NUMBER
8. PERFORMING ORGANIZATION REPORT
NUMBER
ERDC-CERL SR-18-2
KSA database tools. The team concludes
ERDC
ERONSOR/MONITOR'S ACRONYM(S)
11. SPONSOR/MONITOR'S REPORT
NUMBER(S)

5d. PROJECT NUMBER
5e. TASK NUMBER
FY17 LDP2
5f. WORK UNIT NUMBER
8. PERFORMING ORGANIZATION REPORT
NUMBER
ERDC-CERL SR-18-2
KSA database tools. The team concludes
10. SPONSOR/MONITOR'S ACRONYM(S)
ERDC

5d. PROJECT NUMBER
5e. TASK NUMBER
FY17 LDP2
5f. WORK UNIT NUMBER
8. PERFORMING ORGANIZATION REPORT
NUMBER
ERDC-CERL SR-18-2
KSA database tools. The team concludes
ERDC
ERONSOR/MONITOR'S ACRONYM(S)
11. SPONSOR/MONITOR'S REPORT
NUMBER(S)

5d. PROJECT NUMBER
5e. TASK NUMBER
FY17 LDP2
5f. WORK UNIT NUMBER
8. PERFORMING ORGANIZATION REPORT
NUMBER
ERDC-CERL SR-18-2
ESA database tools. The team concludes
wide deployment.
ERDC
11. SPONSOR/MONITOR'S REPORT
NUMBER(S)

\begin{tabular}{l} 
5d. PROJECT NUMBER \\
5e. TASK NUMBER \\
FY17 LDP2 \\
\hline 5f. WORK UNIT NUMBER \\
8. PERFORMING ORGANIZATION REPORT \\
NUMBER \\
ERDC-CERL SR-18-2 \\
KSA database tools. The team concludes \\
-wide deployment. \\
ERDC \\
also enable project managers, researchers, \\
11. SPONSOR/MONITOR'S REPORT \\
NUMBER(S)
\end{tabular}

PROJECT NUMBER
TASK NUMBER
WORK UNIT NUMBER
PERFORMING ORGANIZATION REPORT
NUMBER
RDC-CERL SR-18-2
A database tools. The team concludes
RPONSOR/MONITOR'S ACRONYM(S)
NUMBER(S)

9a. NAME OF RESPONSIBLE PERSON

19b. TELEPHONE NUMBER (include area code) 